\title{
Enhanced DLC Wear Performance by the Presence of Lubricant Additives
}

\author{
Romina Paula de Castro Costa ${ }^{\mathrm{a} *}$, Fernanda Roberta Marciano ${ }^{\mathrm{a}, \mathrm{b}}$, \\ Deiler Antônio Lima Oliveira ${ }^{\text {a }}$ Vladimir Jesus Trava-Airoldi ${ }^{\text {a }}$ \\ anstituto Nacional de Pesquisas Espaciais - INPE, \\ Avenida dos Astronautas 1758, CP 515, São José dos Campos, SP, Brazil \\ ${ }^{\mathrm{b}}$ Universidade do Vale do Paraíba - UNIVAP, \\ Avenida Shishima Hifumi 2911, São José dos Campos, SP, Brazil
}

Received: January 7, 2011; Revised: March 9, 2011

\begin{abstract}
Lubricant additives play significant role for reducing friction and wear of mechanical elements. The additives presented in 5W30 oil were developed for metal surfaces. However, they have been used in engine pieces covered with DLC coatings because they also offer the potential to reduce friction losses and wear in automotive applications. The friction and wear tests were carried out by using a UMT-CETR ball-on-disk tribometer in rotational mode under $5 \mathrm{~W} 30$ synthetic oil at $100{ }^{\circ} \mathrm{C}$. The X-ray photoelectron spectroscopy (XPS) showed the presence of Mo and $\mathrm{S}$ in the wear tracks. These elements are from decomposition of ZDDP and MoDTC additives producing $\mathrm{MoS}_{2}$ in DLC surface, which offers enhanced durability by low wear rate.
\end{abstract}

Keywords: $D L C, M o D T C, Z D D P$, friction

\section{Introduction}

The demand for more compact, efficient and powerful engines has stimulated the undergoing of studies for improvement these technological aspects. Becker (2004) showed that inside the internal combustion engines, $15 \%$ of the total fuel energy is mechanically lost as friction ${ }^{1}$. Podgornik et al. (2003) and Taylor (1998) conducted studies to investigate feasible alternatives towards the enhancement of engine efficiency, such as coatings in certain components, in attempt to minimize friction and wear ${ }^{2,3}$. According to Podgornik (2001) the coatings must have high levels of hardness, wear resistant surfaces, good frictional properties, and maintenance of mechanical resistance 4 .

DLC (diamond-like carbon) is now becoming an option for such coatings, in transportation industry, because they offer the potential to reduce friction losses and wear in automotive applications ${ }^{5-7}$. Some authors ${ }^{3,48}$ mention several studies using DLC coatings in internal combustion engine components because of their excellent tribological behavior in severe environments. DLC has also been mentioned as an applicable coating in valve lifters, obtaining good results for friction and wear ${ }^{9,10}$.

In recent studies, Kalin et al. (2006 and 2007) showed a decrease in the friction coefficient and wear of DLC coatings under lubricated conditions $\mathrm{s}^{11,12}$. They measured the influence of two antiwear additives, an amine phosphate and zinc- dialkyl-dithio-phosphate (ZDDP), on the friction and wear of hydrogenated DLC films ${ }^{11,12}$. The tests were carried out in reciprocating mode, sliding contact at temperatures up to $150{ }^{\circ} \mathrm{C}$. They found that both additives reduced wear at temperatures of $80{ }^{\circ} \mathrm{C}$ and above but that the additives both increased friction ${ }^{11}$. In addition, is known that friction coefficient decreases significantly when using hydrogenated DLC films ${ }^{13,14}$. Erdemir et al. (2005) also showed the importance of considering the surface and lubricant as a single system ${ }^{15}$. They reported that improvements in both friction and wear occur when materials with high lubricity (solid lubricants) are used in systems operating in the boundary lubrication regime. According to Person (1998), Hutchings (1992) and Bayer (1994), the friction coefficient is proportional to viscosity and velocity and inversely proportional to normal force and $\mathrm{hV} / \mathrm{W}$ is proportional to the liquid lubricant thickness ${ }^{16-18}$. The relation between friction coefficient and hV/W is showed by Stribeck diagram (Figure 1). The high load bearing capacity and lubricity of solid lubricants in this regime provide a back-up function to lubricants ${ }^{19}$. However, it is not common for the surface and lubricant to purposely be used in partnership to optimize performance. It is known that wear and friction performance in the boundary lubrication regime is controlled mainly from the lubricant additives which form tribofilms in the contacting surfaces. However, surface treatments and coatings have an important role to play in providing an improved performance or they can in fact eliminate the benefits of the additives. Knowing the details of how surfaces and additives react is paramount in understanding how to achieve optimal lubrication in the boundary regimes. So, the lubrication of DLC-coated substrates can be complicated by variations in DLC chemical composition due to the presence of additives that have been optimized for iron surfaces ${ }^{20}$. The iron absence on DLC films prevents the reaction with additives such as ZDDP and its decomposition products. Some studies show that the low friction coefficient under automotive oil is observed in non-hydrogenated amorphous carbon $(\mathrm{a}-\mathrm{C})^{6}$, as well as the tribofilm formation on DLC surface under poly-alpha-olefin (PAO) lubricant containing a mixture of Mo (Molybdenum) and $\mathrm{ZDDP}^{21,22}$. Haque et al. studied the influence of ZDDP in combination with two types of molybdenum dithio-carbamates (MoDTC) in a reciprocating hydrogenated DLC on cast iron contact ${ }^{23}$. They found that MoDTC-ZDDP reduced friction compared to ZDDP alone and also identified molybdenum disulphide $\left(\mathrm{MoS}_{2}\right)$ and molybdenum trioxide $\left(\mathrm{MoO}_{3}\right)$ on the rubbed DLC surface using X-ray photoelectron spectroscopy (XPS). Using atomic force microscopy (AFM) they also showed that ZDDP formed very thin (2-nm thick) films, which is consisted of short chain zinc pyro and metaphosphate, on the raised regions of the DLC surface ${ }^{24}$.

The main objective of this work is to compare the tribological behavior of $20 \%$ hydrogenated DLC films using carbonitride adhesion interface when lubricated and non-lubricated with 5W30 commercial oil at room temperature and at $100{ }^{\circ} \mathrm{C}$ in the boundary lubrication regime, as well as, the $\mathrm{MoS}_{2}$ formation in the wear track of DLC film. 


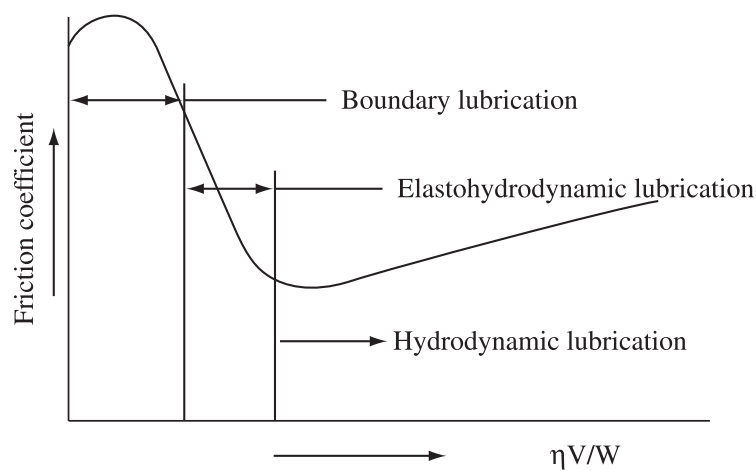

Figure 1. Stribeck diagram.

\section{Experimental Procedures}

This study focuses on the combined effects of material pair and the nature of the lubricant additives.

\subsection{DLC coating preparation}

The DLC films with $20 \%$ hydrogen concentration were deposited by using pulsed-DC discharge under controlled conditions on $316 \mathrm{~L}$ stainless steel substrates using carbonitride diffusion process as interlayer ${ }^{19,25,26}$. The $316 \mathrm{~L}$ stainless steel surface was modified by single diffusion process during one hour at $430{ }^{\circ} \mathrm{C}$ using a mixture of $\mathrm{N}_{2}, \mathrm{H}_{2}$ e $\mathrm{CH}_{4}$ gases. During the first 30 minutes, the carbonitride process was performed in the proportional of $16: 3: 1 \mathrm{~N}_{2}, \mathrm{H}_{2}$ and $\mathrm{CH}_{4}$ gases and 16:3:4 for the last 30 minutes $^{27}$. This carbonitride interlayer has around $10 \mathrm{GPa}$ of hardness and $10 \mu \mathrm{m}$ of thickness ${ }^{27}$. For all tests, the disk specimen surfaces were polished to a final finish of about $0.02 \mu \mathrm{m}$ average roughness $\left(\mathrm{R}_{\mathrm{a}}\right)$. The ball was not submitted by the polishing process, so that it was used with the original roughness about $1.81 \mu \mathrm{m} \mathrm{R}_{\mathrm{a}}$. Both of them were cleaned in ultrasonic acetone bath. The substrates were additionally cleaned by argon discharge with $1 \mathrm{sccm}$ gas flow at $11.3 \mathrm{~Pa}$ working pressure and a discharge voltage of $-700 \mathrm{~V}$ for 30 minutes prior to deposition. The DLC film $20 \%$ hydrogenated was deposited using methane to a thickness of $\sim 2.0 \mu \mathrm{m}$. The deposition was performed using $1 \mathrm{sccm}$ of gas flow, during 2 hours at $11.3 \mathrm{~Pa}$ and a discharge voltage of $-700 \mathrm{~V}$.

\subsection{Sliding test experiments}

The tribological tests were performed for $316 \mathrm{~L}$ pairs. The counterbody and the body (ball and disk, respectively) were coated with DLC film. The $50 \mathrm{~mm}$-diameter disks and the $4 \mathrm{~mm}$-diameter balls were used for the tribological tests. The friction and wear tests were carried out by using a UMT-CETR ball-on-disk tribometer in rotational mode at $120 \mathrm{~mm} / \mathrm{s}$ linear sliding speed under $2 \mathrm{~N}$ of applied load during 1000 cycles. The environment during the tests was strictly controlled to keep humidity at $40 \pm 2 \%$ and temperature at $23 \pm 1{ }^{\circ} \mathrm{C}$, as well as, the number of particles in the clean room at 10000. Figure 2 shows the tribometer in the rotational mode and the schematic design of the tribossystem. The tests were repeated three times for each pair combination. A new position on the ball/disk was used for each test, and the friction coefficient was collected from the steady-state region ${ }^{28}$. The initial average Hertzian contact pressure ranged from 0.73 to $1.09 \mathrm{GPa}$. For the lubricated tests it was used a commercial, Poly-Alpha-Olefin (PAO) synthetic oil (SAE, 5W30 API SL/CF), at room temperature and at $100 \pm 5{ }^{\circ} \mathrm{C}$, according to ASTM D445 norm (Standard Test Method for Kinematic Viscosity). Table 1 shows the main oil properties. After the friction measurements, the ball wear rate was measured and calculated automatically through the optical profiler (Veeco NT1100).

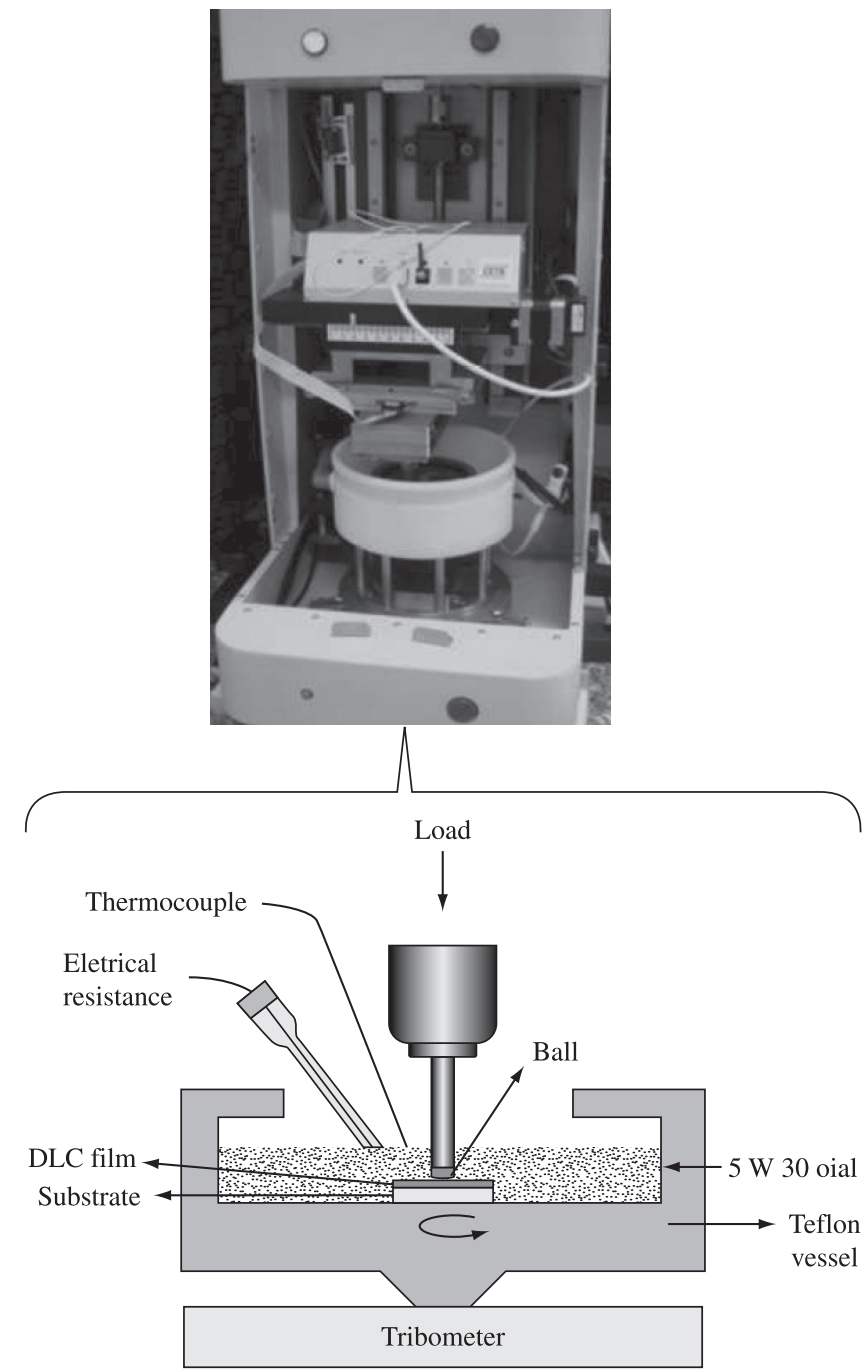

Figure 2. UMT Tribometer in the rotational mode for friction and wear characterizations, as well as, the schematic design of tribossystem used with oil.

Table 1. Oil properties.

\begin{tabular}{cc}
\hline Properties & $5 \mathrm{~W} 30$ \\
\hline Density $\left(20^{\circ} \mathrm{C}\right) \mathrm{g} \cdot \mathrm{cm}^{-3}$ & 0.84 \\
Viscosity $\left(100{ }^{\circ} \mathrm{C}\right) \mathrm{cSt}$ & 11.1 \\
\hline
\end{tabular}

\subsection{Surface analyze experiments}

\subsubsection{X-ray Photoelectron Spectroscopy (XPS)}

X-ray Photoelectron Spectroscopy (XPS) analyses were obtained using a VG 220I apparatus. XPS was performed by a nonmonochromatized source with dual anode for $\mathrm{MgKa} / \mathrm{AlKa}$ irradiation. The size of the X-ray probe was set at $100 \times 100 \mu \mathrm{m}^{2}$. The thickness probed in XPS was about 3-4 nm with exponential decay.

\subsubsection{X-ray Fluorescence (XRF)}

The X-ray Fluorescence (XRF) analysis were performed in order to identify the presence (or absence) of one or more analytes in 5W30 oil, such as, zinc, phosphorous and less commonly copper that are used in antiwear additives. Sulfur, phosphorous and molybdenum are 
common components of extreme-pressure additives; and calcium, barium and magnesium are components of detergent additive packages used in engine oils. This technique was based on the detector system's capability to determine the energy of the photons.

\section{Results and Discussion}

\subsection{Friction and Wear}

Figure 3 shows the friction and wear of DLC/DLC and 316L/DLC pairs in air conditions, under $5 \mathrm{~W} 30$ oil at room temperature and under $5 \mathrm{~W} 30$ at $100{ }^{\circ} \mathrm{C}$. For the DLC/DLC pair in air conditions, the friction was around 0.09, Figure 3a. High contact temperature results in the tribofilm layer formation, graphitization of DLC. The tribofilm is formed due to interstitial diffusion process of hydrogen atoms forward to DLC bulk, increasing $\mathrm{C}-\mathrm{H}$ bonds and conversions of $\mathrm{sp}^{3}$-hybridized $\mathrm{C}$ sites to $\mathrm{sp}^{2}$-hybridized (disordered clusters of $\mathrm{sp}^{2}$ sites). It provides high wear of DLC coating and low friction ${ }^{29,30}$. The 316L/DLC pair in air condition presented a friction coefficient around 0.18 , while the wear rate decreased $20 \%$ compared to DLC/DLC pair in the same condition.

It is interesting to note that, when $5 \mathrm{~W} 30$ oil at room temperature was added on DLC/DLC pair, it did not affect the friction coefficient and the wear rate. Jisheng et al. (1997) also noted this and attributed it to the oil ability to form a layer of carboxylic acid on the DLC

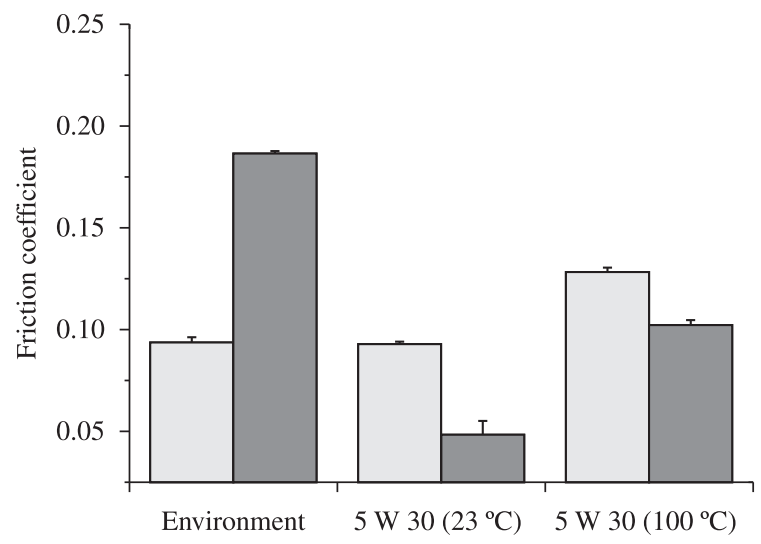

(a)

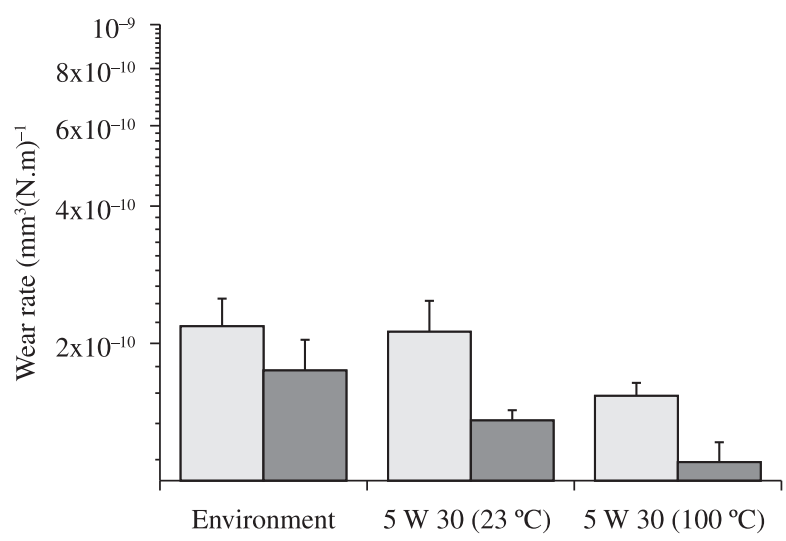

(b)

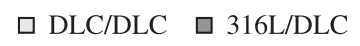

Figure 3. a) Friction coefficient; and b) wear rate of DLC film in environment air, under $5 \mathrm{~W} 30$ oil at room temperature and at $100{ }^{\circ} \mathrm{C}$. surface preventing the tribofilm formation ${ }^{31}$. However, for 316L/DLC pair, it caused a decrease of $55 \%$ in the friction coefficient and $36 \%$ in the wear rate compared to DLC/DLC pair in the same condition. It occurred because both DLC-coated surfaces were separated by a thin oil film at the sliding contact ${ }^{6}$. De Barros Bouchet et al. (2007) also observed the same behavior in their experiments. The reduction mechanism of friction on steel parts has been attributed to the effect of long chain polar molecules, amphiphilic, called Self-Assembled Monolayer (SAM). The polar molecules ends are chemically adsorbed on the native oxide layer presented in the steel surface. The amphiphilic molecules promoted the crystalline structure formation, so that the low friction coefficient was attributed by the easy sliding of methyl groups ${ }^{32}$.

When the $5 \mathrm{~W} 30$ oil at $100{ }^{\circ} \mathrm{C}$ was added on the DLC/DLC and $316 \mathrm{~L} / \mathrm{DLC}$ pairs, the friction coefficient increased to 33 and $150 \%$, respectively, compared to the same pairs with oil at room temperature. This behavior is related to a reduction of fluid viscosity due to the effects of high temperature. When a substantial reduction in fluid viscosity occurs, it promotes asperity contacts (mechanical rubbing) and an increase in the friction coefficient temperature ${ }^{33}$. It occurred by tribochemical interactions of oil additives in DLC surface $^{6}$. On the other hand, DLC/DLC and 316L/DLC pairs showed a particular behavior, the wear rate was decreasing with the increase of temperature. At $100{ }^{\circ} \mathrm{C}$ the DLC/DLC and 316L/DLC pairs showed a decrease of 27 and $20 \%$ in the wear rate compared to the same pairs with oil at room temperature. According to the literature, with increasing temperature the formation of graphitic layer (tribofilm) occurs due to a transformation of $\mathrm{sp}^{2}$ to $\mathrm{sp}^{3}$ phase of DLC coatings in dry sliding conditions ${ }^{34}$. When the oil is added among surfaces in contact, they are separated by a thin layer of carboxylic acid preventing the formation of tribofilm, as well as, reduce the contact temperature and contribute to interactions between oil additives and DLC surface ${ }^{6,10}$.

\subsection{XPS analyses}

In order to understand the role of oil additives on the durability of the DLC coatings, chemical analysis of the tribofilm formed inside of the wear track were performed using XPS. The XPS spectra of the DLC before tests and the tribofilm formed by 5 W30 oil are given in Figure $4 \mathrm{a}$ and $\mathrm{b}$ respectively.

The XPS spectra obtained before friction tests show elements of DLC surface, Table 2. After friction tests, it shows elements coming from additives, as well as, interacting materials of the DLC film.

It is interesting to note that Mo $3 \mathrm{~d}$ peak was found in the top layer of tribofilms formed by $5 \mathrm{~W} 30$ oil, indicating the presence of a compound derived from lubricants. The binding energies of XPS peak of the tribofilm inside of the wear scar and DLC coatings are given in Table 3.

In 5W30 oil, the MoDTC (molybdenum dithio-carbamates) additive decomposed into $\mathrm{MoS}_{2}$ and Mo-oxide, see Figure 4c. $\mathrm{MoS}_{2}$ sheets having very low shear strength provide low friction while the crystalline structure of Mo-oxide provides high friction ${ }^{35,36}$.

However, the formation of molybdenum disulphide, after friction at high temperature promotes the reduction of wear rate due to the formation of lamellar structure with relatively low surface energy. The low presence of water contained in 5W30 oil, Table 4, promotes little hydrogen bonding between the crystallites, decreasing the adhesion between them, which leads to the low wear ${ }^{37}$.

In the case of ZDDP, derived Zn (Zinc) was found in the tribofilm formed inside of wear scar with binding energies of $\mathrm{Zn} 2 \mathrm{p}$, and $\mathrm{O}$ $1 \mathrm{~s}$ indicating the formation of $\mathrm{ZnO} / \mathrm{Zn}$-metaphosphate antiwear compounds $^{38,39}$. It is interesting to note that the formation of $\mathrm{MoS}_{2}$ (molybdenum disulphide) and $\mathrm{ZnO}$ (zinc oxide)/ZnS (zinc blende 


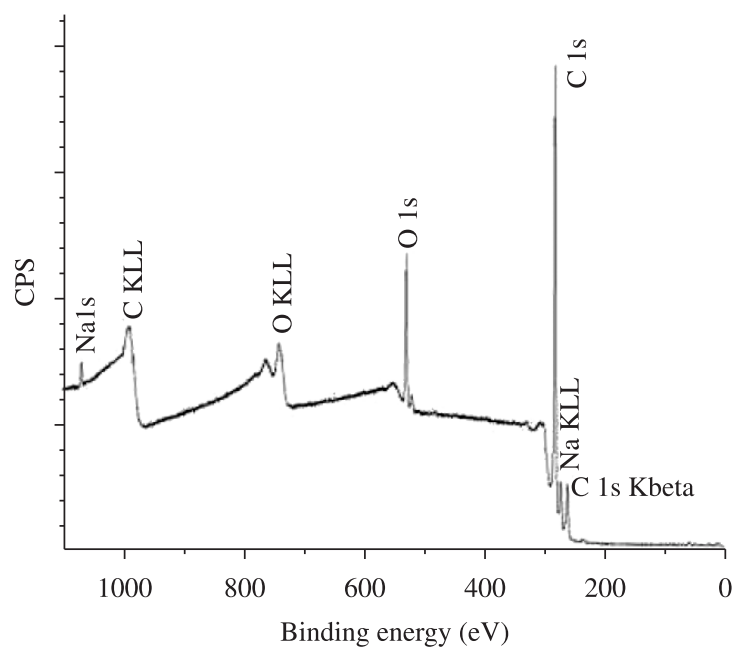

(a)

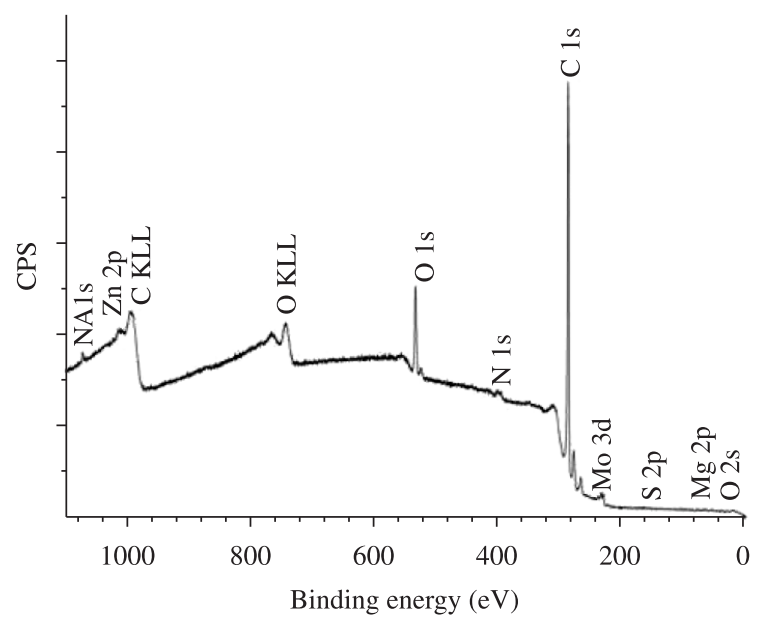

(b)

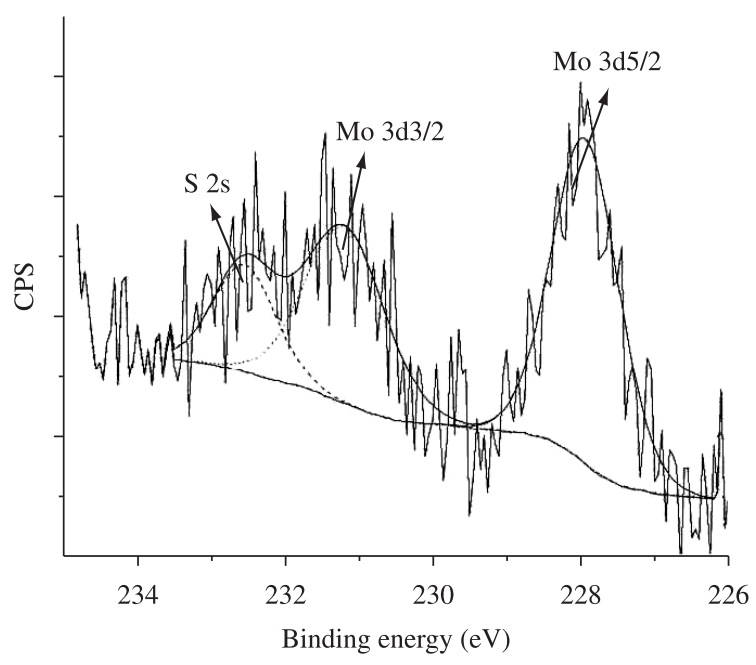

(c)

Figure 4. XPS spectra of DLC film a) before friction tests; $b$ ) after friction test under $5 \mathrm{~W} 30$ oil at $100{ }^{\circ} \mathrm{C}$; and c) after friction test under $5 \mathrm{~W} 30$ oil at $100{ }^{\circ} \mathrm{C}$ showing the presence of Molybdenum between 234 and $226 \mathrm{eV}$.
Table 2. Elements in DLC surface before friction tests.

\begin{tabular}{ccc}
\hline Elements & Binding energy & At\% \\
\hline $\mathrm{C} 1 \mathrm{~s}$ & 285.35 & 87.61 \\
$\mathrm{O} 1 \mathrm{~s}$ & 532.60 & 11.52 \\
$\mathrm{Na} 1 \mathrm{~s}$ & 1071.60 & 0.59 \\
\hline
\end{tabular}

Table 3. Elements in DLC surface after friction tests under $5 \mathrm{~W} 30$ oil at $100^{\circ} \mathrm{C}$.

\begin{tabular}{ccc}
\hline Elements & Blinding energy & At\% \\
\hline $\mathrm{C} 1 \mathrm{~s}$ & 285.15 & 89.90 \\
$\mathrm{O} 1 \mathrm{~s}$ & 532.40 & 8.60 \\
$\mathrm{~N} 1 \mathrm{~s}$ & 399.65 & 0.47 \\
$\mathrm{Na} \mathrm{1s}$ & 1070.65 & 0.23 \\
$\mathrm{Mg} 2 \mathrm{p}$ & 51.65 & 0.50 \\
$\mathrm{~S} 2 \mathrm{p}$ & 161.90 & 0.21 \\
$\mathrm{Zn} \mathrm{2p}$ & 1021.15 & 0.04 \\
$\mathrm{Mo} \mathrm{3d}$ & 227.90 & 0.05 \\
\hline
\end{tabular}

Table 4. Water content of $5 \mathrm{~W} 30$ oil.

\begin{tabular}{cc}
\hline Oil & $\mathrm{H}_{2} \mathrm{O}(\mathrm{ppm})$ \\
\hline $5 \mathrm{~W} 30$ & 952.4 \\
\hline
\end{tabular}

Table 5. Compound concentration of additives elements in 5W30 oil.

\begin{tabular}{c}
\hline Quantification of sample 5W30 oil \\
\hline Compound Conc. (\%) \\
\hline P 0.230 \\
S 0.788 \\
Ca 2.330 \\
Zn 2.584 \\
Mo 0.634 \\
\hline
\end{tabular}

or sphalerite) compounds in the DLC surface inside of the wear scar was caused by shearing and contact of the asperities, so the friction is needed to produce these speciation's ${ }^{40}$.

\subsection{X-Ray Fluorescence}

In order to evaluate the additives contained in 5W30 oil, X-Ray Fluorescence analyses was performed. The chemical compositions of additives are summarized in Table 5 by elements as percent of total mass of the oils. Zn (Zinc), P (Phosphorus), Ca (Calcium), $\mathrm{S}$ (Sulphur) and Mo (Molybdenum) were the predominant elements in the $5 \mathrm{~W} 30$ oil. It is in agreement with elements that were showed by XPS analyses inside of wear scar at high temperature.

\section{Conclusions}

The 20\% hydrogenated DLC film showed compatibility with the oil, reaching low friction coefficient and wear rate values. Also, the DLC film responded differently to changes in temperature of the $5 \mathrm{~W} 30$ oil. The tribofilm was identified in the DLC surface, as well as, it graphitization after friction tests. The increase of temperature to $100{ }^{\circ} \mathrm{C}$ promotes the formation of a tribofilm composed by sulfides and oxides of molybdenum and Zinc. In general, the best results were obtained for the 316L/DLC pair (when only one surface was coated with DLC film). 
In addition, from this study it is possible to conclude that:

1. The $\mathrm{MoS}_{2}, \mathrm{ZnO}$ and $\mathrm{ZnS}$ compounds formation in the DLC track surface is derived from MoDTC and ZDDP decomposition.

2. The increase of friction coefficient at high temperature is attributed to the reduction of 5W30 viscosity, which leads to increasing contact asperities.

3. The wear rate decreased inversely proportional to the increase of temperature for DLC/DLC and 316L/DLC pairs.

\section{Acknowledgements}

The authors are very grateful to Conselho Nacional de Desenvolvimento Científico e Tecnológico (CNPq) and Fundação de Amparo à Pesquisa do Estado de São Paulo (FAPESP) for the financial support.

\section{References}

1. Becker EP. Trends in tribological materials and engine technology. Tribology International. 2004; 37(7):569-575. doi:10.1016/j.triboint.2003.12.006.

2. Podgornik B and Vizintin J. Tribology of thin films and their use in the field of machine elements. Vacuum. 2003; 68:39-47. doi:10.1016/S0042207X(02)00282-8.

3. Taylor CM. Automobile engine tribology - design considerations for efficiency and durability. Wear. 1998; 221:1-8. doi:10.1016/S00431648(98)00253-1.

4. Podgornik B. Coated machine elements - fiction or reality? Surface \& Coatings Technology. 2001; 146-147:318-323. doi:10.1016/S02578972(01)01400-1.

5. Kano M. DLC Coating Technology Applied to Sliding Parts of Automotive Engine. New Diamond and Frontier Technology. 2006; 16(4):201-210.

6. Neville A, Morina A, Haque T and Voong M. Compatibility between tribological surfaces and lubricant additives - How friction and wear reduction can be controlled by surface/lube synergies. Tribology International. 2007; 40:1680-1695. doi:10.1016/j.triboint.2007.01.019.

7. Gahlin R, Larsson $\mathrm{M}$ and Hedenqvist P. ME-C:H coatings in motor vehicles. Wear. 2001; 249(3-4):302-309. doi:10.1016/S0043-1648(01)00565-8.

8. Malaczynski GW, Hamdi AH, Elmoursi AA and Qiu X. Diamondlike carbon coating for aluminum 390 alloy - automotive applications. Surface and Coatings Technology. 1997; 93:280-286. doi:10.1016/S02578972(97)00061-3.

9. Kodai A, Mori T and Inukai T. Applying Hard thin coatings to tappets to reduce friction. In: SAE Paper 2001-01-1886/4299. 2001.

10. Yasuda Y, Kano M, Mabuchi Y and Abou S. Research on diamond-like carbon coatings for low-friction valve lifters. In: SAE Technical Papers Series. 10.4271/2003-01-1101. 2003.

11. Kalin M, Roman E and Vizintin J. The effect of temperature on the tribological mechanism and reactivity of hydrogenated amorphous diamondlike carbono coatings under oil lubricated conditions. Thin Solid Films. 2007; 515:3644-3652. doi:10.1016/j.tsf.2006.09.049.

12. Kalin M and Vižintin J. A comparison of the tribological behavior of steel/ steel, steel/DLC and DLC/DLC contacts when lubricated with mineral and biodegradable oils. Wear. 2006; 261:22-31. doi:10.1016/j.wear.2005.09.006.

13. Erdemir A. The role of hydrogen in tribological properties of diamond-like carbon films. Surface and Coatings Technology. 2001; 146-147:292-297. doi:10.1016/S0257-8972(01)01417-7.

14. Robertson J. Diamond-like amorphous carbon. Materials Science and Engineering: R: Reports. 2002; 37(4-6):129-281. doi:10.1016/S0927796X(02)00005-0.

15. Erdemir A. Review of engineered tribological interfaces for improved boundary lubrication. Tribology International. 2005; 38:249-256. doi:10.1016/j.triboint.2004.08.008.

16. Persson BNJ. Sliding friction. Surface Science Reports. 1999; 33:83-119. doi:10.1016/S0167-5729(98)00009-0.

17. Hutchings IM. Tribology: friction and wear of engineering materials. London: Edward Arnold; 1992. p. 273.

18. Bayer RG. Mechanical wear prediction and prevention. New York: Ed. Marcel; 1994. p. 657. Dekker.
19. Bonetti LF. Adhesion studies of diamond-like carbon films deposited on Ti6Al4V substrate with a silicon interlayer. Thin Solid Films. 2006; 515(1):36,55-36,59.

20. Erdemir and Donnet C. Tribology of diamond- like carbon films: recente progress and future prospects. Applied physics. 2006; 39(18):R311-R327.

21. De Barros Bouchet MI, Martin JM, Le-Mogne T and Vacher B. Boundary lubrication mechanisms of carbon coatings by MoDTC and ZDDP additives.Tribology International. 2005; 38:257-264. doi:10.1016/j. triboint.2004.08.009.

22. Equey S, Roos S, Mueller U, Hauert R, SpenceR ND and Crockett R. Tribofilm formation from ZnDTP on diamond-like carbon. Wear. 2008; 264(3-4):316-321. doi:10.1016/j.wear.2007.03.012.

23. Haque T, Morina A, Neville A, Kapadia R and Arrowsmith S. Non-ferrous coating/lubricant interactions in tribological contacts: assessment of tribofilms. Tribology International. 2007; 40:1603-1612. doi:10.1016/j. triboint.2007.01.023.

24. Haque T, Morina A, Neville A, Kapadia R and Arrowsmith S. Study of the ZDDP antiwear tribofilm formed on the DLC coating using AFM and XPS. Journal ASTM International. 2007; 4(7):12 p.

25. Trava-Airoldi VJ, Bonetti LF, Rodrigues GC, Fernandes JA, Blando E, Hübler R et al. DLC film properties obtained by a low cost and modified pulsed-DC discharge. Thin Solid Films. 2007; 516(2-4):272-276. doi:10.1016/j.tsf.2007.06.100.

26. Capote G, Bonetti LF, Santos LV, Trava-Airoldi VJ, Corat EJ. Adherent amorphous hydrogenated carbon films on metals deposited by PECVD. Thin Solid Films. 2008; 516:4011-4017. doi:10.1016/j.tsf.2007.08.007.

27. Statuti RPCC, Radi PA, Santos LV and Trava-Airoldi VJ. A Tribological Study of the Hybrid Lubrication of DLC Films with Oil and Water. Wear. 2009; 267:1208-1213. doi:10.1016/j.wear.2008.11.033.

28. Eryilmaz OL and Erdemir A. Investigation of initial and steady-state sliding behavior of a nearly-frictionless carbon film by imaging 2- and 3-D TOFSIMS. Tribology Letters. 2007; 28(3):241-249. doi:10.1007/s11249-0079268-z.

29. Donnet C. Recent progress on the tribology of doped diamond-like and carbono alloy coating. Surface Coatings Technology. 1998; 100-101:180186. doi:10.1016/S0257-8972(97)00611-7.

30. Fontaine J, Donnet C, Grill A and Lemogne T. Tribochemistry between Hydrogen and Diamond-Like Carbon Films. Surface and Coatings Technology. 2001; 146-147:286-291. doi:10.1016/S0257-8972(01)01398-6.

31. Jisheng E and Gawne CT. Wear characteristics of plasma-nitrided CrMo steel under mixed and boundary conditions. Journal of Materials Science. 1997; 32:913-920. doi:10.1023/A:1018549516137.

32. De Barros Bouchet MIB, Matta C, Le-Mogne T, Martin JM, Zhang Q, Goddard III W. et al. Superlubricity mechanism of diamond-like carbon with glycerol: Coupling of experimental and simulation studies. Journal of Physics: Conference Series. 2007; 89(1):03-12. doi:10.1088/17426596/89/1/012003.

33. Andersson $\mathrm{S}$ and Salas-Russo $\mathrm{E}$. The influence of surface roughness and oil viscosity on the transition in mixed lubricated sliding steel contacts. Wear. 1994; 174(1-2):71-79. doi:10.1016/0043-1648(94)90088-4.

34. Voevodin AA, Zabinski JS. Nanocomposite and nanostructured tribological materials for space applications. Composites Science and Technology. 2005; 65(5):741-748.

35. Morina A, Neville A, Priest M and Green JH. ZDDP and MoDTC interactions and their effect on tribological performance-tribofilm characteristics and its evolution. Tribology Letters. 2006; 24(3):243. doi:10.1007/s11249-0069123-7.

36. Grossiord C, Varlot K, Martin JM, Esnouf C and Inoue K. MoS2 single sheet lubrication by molybdenum dithiocarbamate. Tribology International. 1998; 31:737-43. doi:10.1016/S0301-679X(98)00094-2.

37. Wahl KJ, Belin M, Singer IL. A triboscopic investigation of the wear and friction of MoS2 in a reciprocating sliding contact. Wear. 1998; 214(2):212-220. doi:10.1016/S0043-1648(97)00246-9.

38. Martin JM. Antiwear mechanisms of zinc dithiophosphate: a chemical hardness approach. Tribology Letters. 1999; 6:1-8. doi:10.1023/A:1019191019134.

39. Martin JM, Grossiord C, Mogne TL, Bec S and Tonck A. The two-layer structure of Zndtp tribofilms Part I. AES, XPS and XANES analyses. Tribology International. 2001; 34:523-530. doi:10.1016/S0301679X(01)00029-9.

40. Martin JM. Lubricant additives and the chemistry of rubbing surfaces: metal dithiophosphates triboreaction films revisited. Japanese Journal of Tribology. 1997; 42(9):1102-1104. 